\title{
Polarity transitions during neurogenesis and germinal zone exit in the developing central nervous system
}

\author{
Shalini Singh and David J. Solecki * \\ Department of Developmental Neurobiology, St. Jude Children's Research Hospital, Memphis, TN, USA
}

\section{Edited by:}

Takeshi Kawauchi, Keio University School of Medicine/PRESTO, JST, Japan

\section{Reviewed by:}

Orly Reiner, Weizmann Institute of Science, Israel

Yasuhiro Itoh, Harvard University, USA

\section{*Correspondence:}

David J. Solecki, Department of Developmental Neurobiology D2025C, St. Jude Children's Research Hospital, 262 Danny Thomas Place-MS 323, Memphis, TN 38105, USA

e-mail:david.solecki@stjude.org
During neural development, billions of neurons differentiate, polarize, migrate and form synapses in a precisely choreographed sequence. These precise developmental events are accompanied by discreet transitions in cellular polarity. While radial glial neural stem cells are highly polarized, transiently amplifying neural progenitors are less polarized after delaminating from their parental stem cell. Moreover, preceding their radial migration to a final laminar position neural progenitors re-adopt a polarized morphology before they embarking on their journey along a glial guide to the destination where they will fully mature. In this review, we will compare and contrast the key polarity transitions of cells derived from a neuroepithelium to the well-characterized polarity transitions that occur in true epithelia. We will highlight recent advances in the field that shows that neuronal progenitor delamination from germinal zone (GZ) niche shares similarities to an epithelialmesenchymal transition. Moreover, studies in the cerebellum suggest the acquisition of radial migration and polarity in transiently amplifying neural progenitors share similarities to mesenchymal-epithelial transitions. Where applicable, we will compare and contrast the precise molecular mechanisms used by epithelial cells and neuronal progenitors to control plasticity in cell polarity during their distinct developmental programs.

Keywords: neurogenesis, neuronal progenitor, neuroepithelial, neuronal polarity, cell junction, epithelial mesenchymal transition, delamination

\section{INTRODUCTION}

The developing central nervous system, including the spinal cord, retina and brain, occupies a complex developmental landscape wherein neural stem cells are born and then proliferate, differentiate and migrate long distances to form intricate networks, all of which ensure proper CNS functioning. Notably, almost all of the diverse cell types comprising the CNS originate from the neuroepithelium lining the embryonic neural tube and neural plate. Self-renewing multipotent cells (neural stem cells) orient themselves along the apical-basal axis in a single layer, conferring a highly polarized structure on this germinal niche. Subsequent symmetric and asymmetric division of the neural stem cells imparts a pseudostratified appearance to neuroepithelium, in which the nuclei undergo interkinetic nuclear migration while the apical-basal surfaces of the cells remain anchored through intercellular junctions (Figure 1A; Haubensak et al., 2004; Götz and Huttner, 2005). Alteration of polarity signaling cascade or cell adhesion dynamics leading to improper neural development substantiates the architectural organization of the neuroepithelium (Ayala et al., 2007; Métin et al., 2008; Roussel and Hatten, 2011). As development proceeds these progenitors must commit to a specific neuronal fate and migrate to their final destinations. This step requires them to sever ties with the ventricular zone (VZ), undergo a transition in polarity, change their adhesive preference and delaminate. Our understanding of key components and signaling cascades, such as the Par polarity complex and its interplay with adhesion molecules such as cadherins, nectins, claudins and junctional adhesion molecules (JAMs), has advanced considerably (Tsukita and Furuse, 1999; Mizoguchi et al., 2002; Costa et al., 2008; Ishiuchi et al., 2009; Famulski et al., 2010), but some key questions remain, including: What are the specific biological processes that precede delamination? What initiates and controls the switch in polarity and how is this linked to adherens junction (AJ) disassembly? Epithelial cells frequently display polar plasticity through processes known as epithelial-to-mesenchymal transition (EMT) and its reverse, mesenchymal-to-epithelial transition (MET), which developing neurons appear to mirror. By highlighting recent work addressing these specific challenges in the developing cortex, spinal cord, retina and cerebellum, we will highlight the emerging idea that akin to epithelial cells, progenitors in the GZs of the CNS require the EMT-MET machinery to undergo a change in polarity that leads to their delamination, differentiation and maturation.

\section{DEVELOPING NEOCORTEX}

Development of the neocortex, with its unique lamination process, provides an attractive model to investigate the cellular remodeling essential for establishing the CNS (Rakic, 1971, 2009). Neural stem cells at the transient embryonic zone switch from a proliferative symmetric cell division phase to an asymmetric 


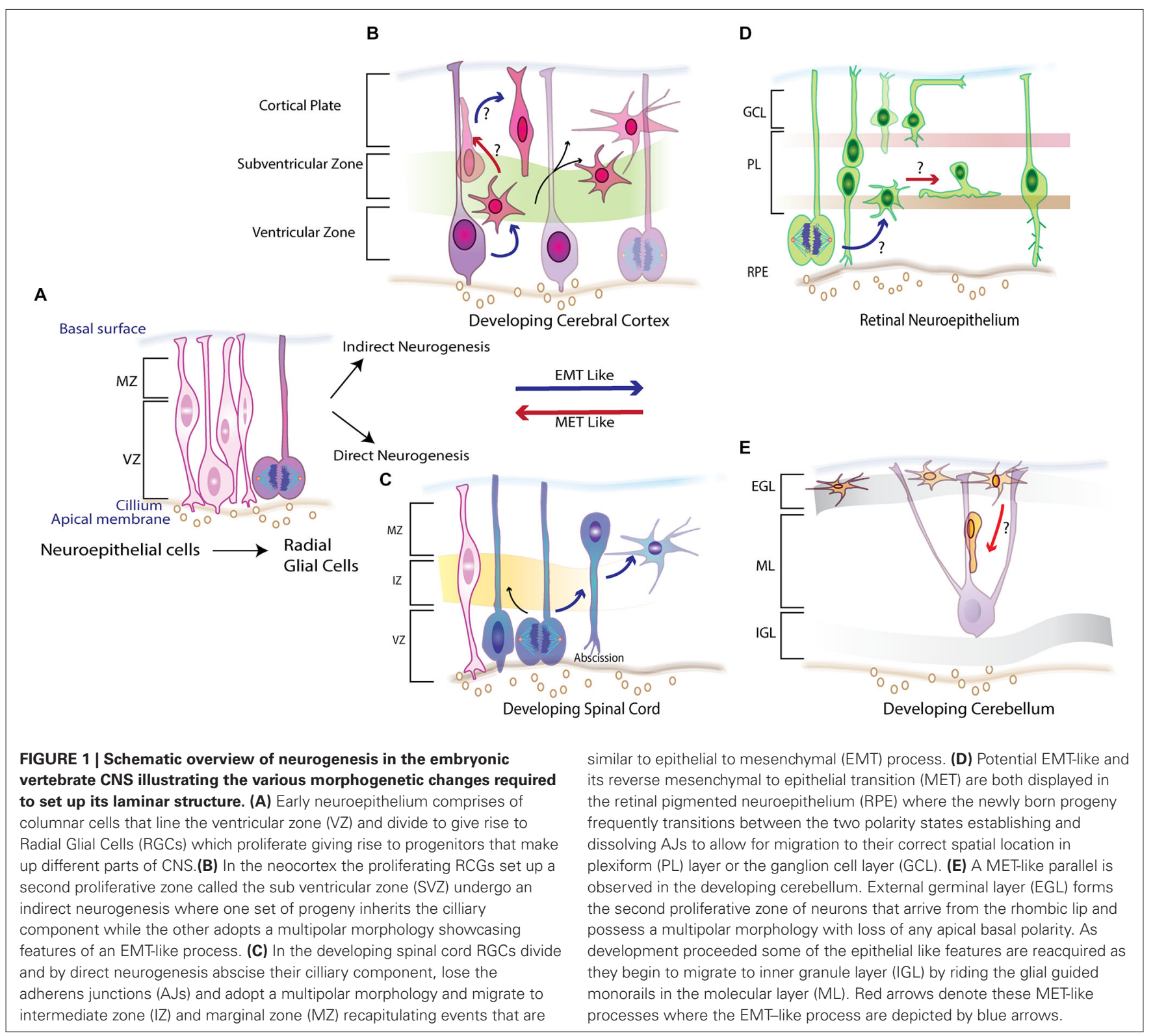

phase, giving rise to radial glial cells (RGCs), the progenitor cells of the cortex (Bayer, 1986, 1990; Malatesta et al., 2000; Campbell and Götz, 2002; Nadarajah and Parnavelas, 2002; Götz, 2003). Successive waves of migration at the VZ form an insideout gradient of neurogenesis to establish the laminar cortical structure (Figure 1B; Angevine and Sidman, 1961). Stratification of the cortex requires radial and tangential migration of neurons, as shown by electron microscopy, lineage tracing and realtime imaging of brain slices (Mione et al., 1997; Wilson and Rubenstein, 2000; Marín and Rubenstein, 2001). Lamination of the cortex in CNS development requires precise spatial-temporal regulation of cortical migration (Métin et al., 2008). To guide the reader's appreciation and understanding of the morphogenetic changes that occur during corticogenesis, we will briefly discuss the cytoarchitecture of the newly formed RGCs.
Ultrastructure studies show that like epithelial cells, newly formed RGCs are morphologically polarized (Aaku-Saraste et al., 1996; Huttner and Brand, 1997; Chenn et al., 1998). They attach apically to the ventricular surface while extending long basal processes that span the entire cortical plate that affix at the overlying matrix produced by the pia. Apical anchoring is mediated by specialized intercellular adhesion complexes that involve cadherins, nectins, JAMs and $\beta$-catenin (Aaku-Saraste et al., 1996; Zhadanov et al., 1999; Manabe et al., 2002; Junghans et al., 2005; Kadowaki et al., 2007). These complexes link the cytoskeletal scaffolds and coordinate signaling pathways in neighboring cells while the pial attachment is established by integrins and possibly cadherins (Anton et al., 1999; Graus-Porta et al., 2001). Relevance of the cell-cell contact in establishing the radial glial scaffold at the apical surface and its role in 


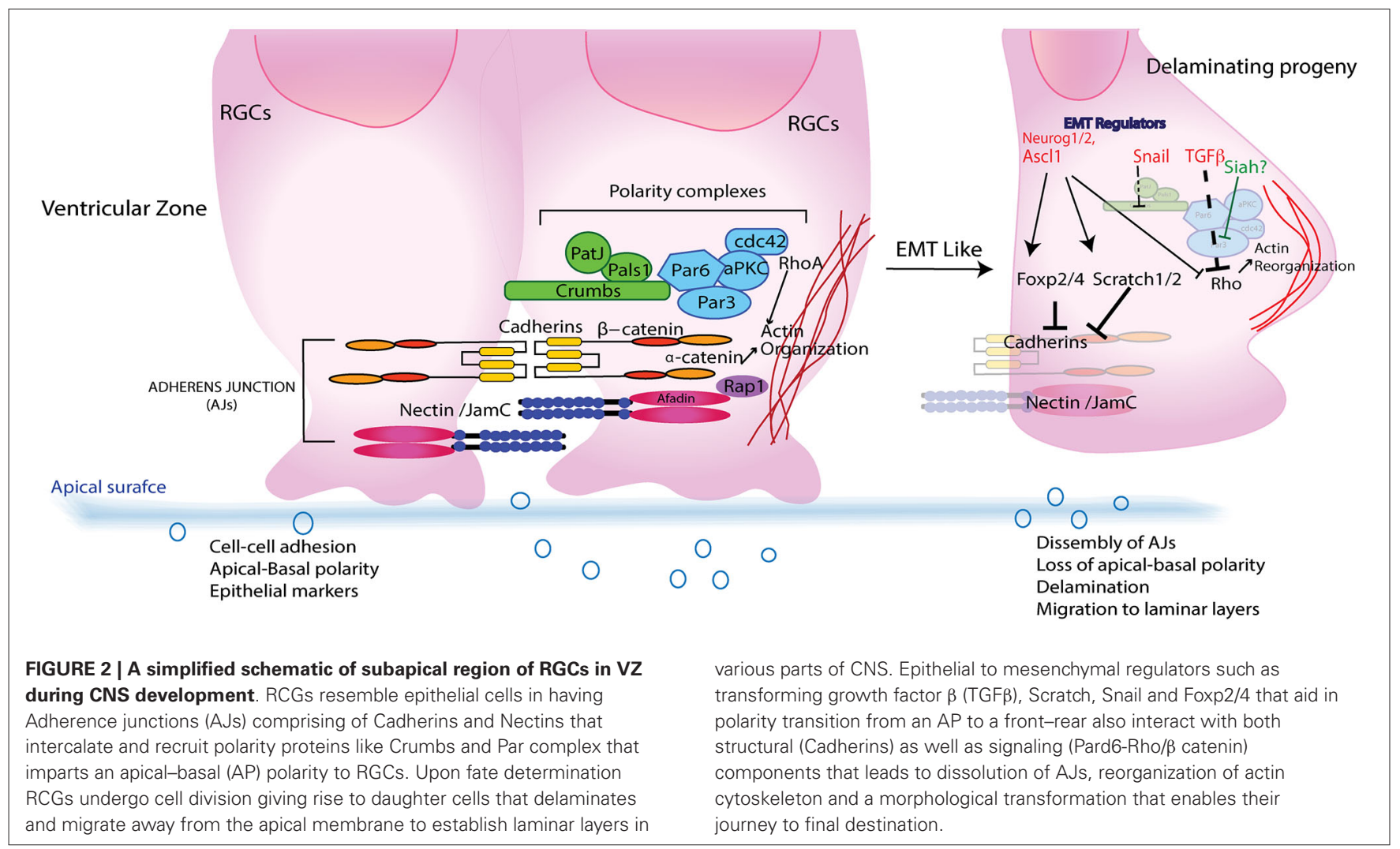

signaling networks such as reelin is highlighted by cortical defects observed in $\beta$ 1integrin and Dab1/Rap1/cadherin deficient mice (Graus-Porta et al., 2001; Franco et al., 2011). As in epithelial cells, Cdc42 and polarity complexes such as Par proteins and Crumbs complex (Crb, PALS, PATJ, Lin7) are essential in establishing and maintaining these AJs (Figure 2; Manabe et al., 2002; Cappello et al., 2006; Imai et al., 2006; Bultje et al., 2009). Nevertheless, as development proceeds the RGCs divide giving rise to a progeny that become committed to their fate and must migrate to occupy their respective positions in the cortical layers. It appears that the newly born neurons must first break their $\mathrm{AJs}$ to delaminate from the apical surface. Second, they must remodel their cytoskeletons to initiate movement out of the VZ. Remodeling of polarity is apparent from time-lapse imaging and electron microscopy that show migrating neurons adopting an intermediate multipolar state before reacquiring some of the features needed for glialguided migration (Shoukimas and Hinds, 1978; Nadarajah et al., 2003). Remodeling of junctions and polarity in these newly born neurons closely resemble the sequence of events during EMT-MET in epithelial cells (Figure 1B; Nelson, 2009; Lamouille et al., 2014).

Given that apical anchoring and delamination are crucial to cortical arrangement there has been great focus on understanding the apical protein complexes that allow for this GZ exit; and have helped to define the roles of $\mathrm{N}$-cadherin/Rap1, adaptor protein Afadin, Lis $1, \beta$-catenin, cdc42/GSK-3 $\beta$ and polarity protein Pard3/Notch in maintaining the apical cytoarchitecture
(Bos et al., 2001; Ooshio et al., 2007; Bi et al., 2009; Severson et al., 2009; Yokota et al., 2010; Franco et al., 2011; Jossin, 2011; Jossin and Cooper, 2011). A recent report showed that cadherinbased adhesions also facilitate Notch signaling (Hatakeyama et al., 2014). While these studies have identified key components of the machinery involved in establishing the polarity and GZ occupancy, the overarching question of how these components might be regulated demands attention. Because fate commitment and delamination are sequential events, it seemed plausible that proneural genes might also have a role in regulating delamination. Actin reorganization by proneural factors such as Neurogenin 2 (Neurog2) and Ascl1, activating Rho GTPases Rnd2 and Rnd3, respectively, allows remodeling of the actin cytoskeleton by inhibiting Rho activity, thus linking neuronal commitment and migration (Ge et al., 2006; Heng et al., 2008; Pacary et al., 2011). Although they may provide the physical force needed for RGC exit from the GZ niche, they do not initiate delamination, as silencing of Rnd 3 disrupts the distribution of $\beta$-catenin and $\mathrm{N}$-cadherin at AJs, indicating that Rnd 3 is essential for maintaining the integrity of the junctions (Figure 2; Pacary et al., 2011, 2013). Additionally, the physical forces can be effective only if the RGCs first attenuate their intercellular adhesion through dissolution of AJs, lose their apical-basal polarity and acquire a multipolar nature. In neural crest cells and epithelial cells, this phenomenon is regulated by EMT factors that promote loss of epithelial characteristics and acquisition of mesenchymal attributes (Thiery and Sleeman, 2006; Baum et al., 2008). Central to this process are the Snail, Slug and Zeb family of transcriptional repressors (Chaffer et al., 
2007; Baum et al., 2008). From these systems and the fact that newly committed neurons express such regulators, one can extrapolate a possible molecular link between commitment and delamination.

In support of the above idea, Scratch 1 and Scratch 2, members of the Snail superfamily, are expressed upon neuronal fate commitment in neocortex, in which they trigger active disintegration of AJs by directly repressing expression of Ecadherin (Figure 2; Itoh et al., 2013). Additionally, classical genes in the EMT pathway, such as those encoding Occludin and Nephrins, also show downregulation accompanied by increased expression of Mmp19 (Thiery and Sleeman, 2006; Itoh et al., 2013). Notably, Scratch1 overexpression has no effect on neurogenesis, thus identifying it as a delamination-specific pathway. The existence of an EMT-like pathway in corticogenesis is further buttressed by the finding that another regulator of the pathway, Snail, is expressed in both radial precursors and newborn neurons during corticogenesis (Zander et al., 2014a,b). Snail's role in the neocortex is not limited to regulating AJs; it also helps promote the survival, proliferation and self-renewal of cortical progenitors.

\section{DEVELOPING SPINAL CORD}

The central question of what molecular mechanism controls AJ disassembly during migration has been addressed in developing motor neurons (MNs) of the spinal cord. Spinal cord development is a multistage process with distinct subtypes V0, V1, V2, V3, interneurons and MNs (Figure 1C; Alaynick et al., 2011). Convergent action of morphogens such as Shh and retinoic acid elicits a unique set of transcriptional networks and factors (e.g., Olig2) that specify different neuronal subtypes (Mukouyama et al., 2006; Briscoe and Novitch, 2008). Studies in Olig2-mutant mice showed that the forkhead proteins Foxp1, 2 and 4 are essential for specifying $\mathrm{MN}$ fate and for migration (Ferland et al., 2003; Dasen et al., 2008; Rousso et al., 2008; Palmesino et al., 2010). Rousso et al. investigated the role of Foxp proteins in chicken and mouse spinal cord, showing them to be components of a gene regulatory network that links and balances AJs with cell fate (Rousso et al., 2012). Increased expression of Foxp2 and Foxp4 inversely affected expression of $\mathrm{N}$-cadherin and Sox2, leading to dissolution of AJs and ectopic neurogenesis in the VZ. Conversely, their loss maintained the precursors in the progenitor state (Figure 2). Such transcriptional regulation of $\mathrm{N}$-cadherin and Sox 2 might also regulate the size of the embryonic VZ niche by controlling delamination (Rousso et al., 2012). Decreased Sox 2 and cadherin levels have also been demonstrated in neural crest cells before delamination (Zappone et al., 2000; Bylund et al., 2003; Graham et al., 2003; Bello et al., 2012). These findings, together with the documented role of forkhead proteins in maintaining AJs in other systems by regulating cadherins, reinforces the idea of an EMT-like signature in CNS development (Figure 1C; Mani et al., 2007; Rousso et al., 2012).

Besides transcriptional control of adhesion proteins, delamination of progenitors also involves a change in polarity and cellular architecture, recently addressed in a new light by Das and Storey. By using structured illumination microscopy in chick neural tube, they discovered a cellular mechanism called apical abscission that participates in actin-myosin-dependent remodeling of primary cilium (Das and Storey, 2014). Apical abscission at the $\mathrm{VZ}$ detaches progenitors and leads to loss of apical complex proteins, a process characterizing loss of apical polarity (Farkas and Huttner, 2008; Das and Storey, 2012). This study answered the question of how the VZ, unlike archetypal epithelium undergoing EMT, maintains its integrity. It seems plausible that apical abscission might provide the progenitors an efficient way to transiently change their polarity without substantially altering their transcriptional profiles. If basal progenitors remodel their primary cilia in preparation for delamination in the neocortex and for apical shedding of MNs that could explain how newly differentiated neurons lose and reacquire polarity during delamination and migration by remodeling their apical complex proteins.

\section{DEVELOPING RETINA}

Like other developing CNS structures, the retinal neuroepithelium is pseudostratified. During retinogenesis, polarized progenitors remain anchored to the apical-basal membrane by AJs and TJs while their fate is determined by interkinetic nuclear migration (Figure 1D; Frade, 2002; Baye and Link, 2007, 2008). Subsequent establishment of the retinal layers requires postmitotic detachment of retinal progenitors from the apical surface, reorganization of polarity and migration to the appropriate layers (Miyata, 2008).

In mouse retinal progenitors, polarity is imparted by two apical complexes, the partitioning defect (PARD) complex comprising Pard3, Pard6, aPKC and cdc42 and crumbshomologue (CRB) comprising Crb1-3, Pals1/MPP5 and Patj (Koike et al., 2005; Cappello et al., 2006; van de Pavert et al., 2007; Park et al., 2011; Alves et al., 2013; Dudok et al., 2013; Heynen et al., 2013). In mice lacking CRB2, early retinal progenitors show abnormal lamination due to greater proliferation of lastborn progenitors. Membrane-palmitoylated protein 3 (MPP3), a scaffolding cell-cell adhesion protein, is also localized to the retinal sub-apical region and interacts with Pals1 and Dlg1 (Pellikka et al., 2002; Alves et al., 2013). Perturbation of MPP3 in developing retina was found to cause focal disruption of AJs and ectopic cell localization (Dudok et al., 2013). The need to maintain polarity is further stressed by laminar defects in Pals1 conditional-knockout mice, in which mislocalization of neurons was found throughout the retina (Park et al., 2011). Additionally, dysregulation of aPKC and cdc42 lead to lamination defects (Koike et al., 2005; Heynen et al., 2013).

Structural and signaling components come together at neural junctions. In vertebrates, the polarized epithelium's apical junction proteins, such as cadherin, occludins, claudins and JAMs, interact on the cytoplasmic side of the cell with a variety of polarity and signaling molecules, including Pard 3 and $\beta$ catenin, that connect them to the actin cytoskeleton (Tsukita and Furuse, 1999; Tsukita et al., 1999; Nishimura et al., 2004; Umeda et al., 2004; Perez-Moreno and Fuchs, 2006). In the retina, alteration of $\beta$-catenin causes loss of polarity and adhesion, cell detachment, ectopic migration and spatiotemporally perturbed 
retinogenesis (Brault et al., 2001; Fu et al., 2006). The role of apical complexes is exemplified in retinogenesis, in which they not only establish adhesion and polarity but act as important nodes for diverse signaling pathways (e.g., Notch, Wnt, Hippo, mTOR) essential for specifying retinogenesis. As supporting evidence, Ohata et al., showed that Crb complex and Notch form a positive feedback loop that maintains apicobasal polarity; disruption of feedback causes laminar defects (Ohata et al., 2011).

There are some interesting differences between retinal neuroepithelium and other developing CNS structures, one of which was highlighted by Ivanovitch et al. By combining mosaic labeling of single cells with $4 \mathrm{D}$ confocal imaging during optic evagination in zebrafish, they showed two discrete populations of cells: basally positioned cells and core cells involved in establishing the retinal neuroepithelium (Ivanovitch et al., 2013). Interestingly, live imaging showed that basally positioned cells undergo precocious polarization, while core cells remain mesenchymal until optic vesicle formation. The authors found that core cells that localize Pard 3 in a polarized manner undergo a special MET using apical points for intercalation in CNS outpocketing. Furthermore, modulation of Pard $6 \gamma \mathrm{b}$ and Laminin leads to failure of optic vesicle evagination (Ivanovitch et al., 2013).

Clearly, the transition in polarity and morphology of retinal progenitors requires rearrangement of their cytoskeleton that generates physical forces required for movement. While this process is a quintessential requirement for determining the laminar structure of developing CNS, how are such processes regulated remains an open question. A chemical mutagenesis screen in medaka fish identified the guanine-nucleotide exchange factor ArhGEF18, a RhoA- and Rac-specific GEF factor, to be a key regulator of retinal architecture and function that also controls apicobasal polarity and proliferation (Herder et al., 2013; Loosli, 2013). In epithelial cells, small GTPases of the Rho family act as molecular switches that regulate and coordinate the actin cytoskeleton, cell junction assembly and polarity (Heasman and Ridley, 2008; Samarin and Nusrat, 2009). Additionally, Rho GTPases are regulated by transforming growth factor $\beta$ (TGF $\beta$ ), which degrades RhoA by phosphorylating Pard6 (Ozdamar et al., 2005). TGF $\beta$ also downregulates Pard 3 expression while activating the EMT regulator Snail (Figure 2; Wang et al., 2008). As TGF $\beta$ is expressed during early retinal embryogenesis, it could plausibly play a role in regulating or guiding a similar process at that time.

\section{DEVELOPING CEREBELLUM}

The cerebellum is an attractive model for studies of CNS development, primarily because of its remarkably simple laminar organization, which consists of two principal neurons (cerebellar granule neurons (CGNs) and Purkinje cells) and minority interneuronal populations (Roussel and Hatten, 2011). Granule neuron progenitors (GNPs) arise along the rhombic lip, at the midbrain-hindbrain junction, and migrate dorsally over the cerebellar anlage (Wingate, 2001), while a stream of radially migrating progenitors arising from neuroepithelium form the other cerebellar cell types (Hallonet and Le Douarin, 1993; Gao and Hatten, 1994). After GNPs migrate away from the rhombic lip, they proliferate under the guidance of external cues, such as Shh, to generate a second GZ called the external granular layer (EGL; Hatten, 1999). The remaining cerebellar histogenesis occurs mainly postnatally. This protracted development provides an excellent opportunity to study distinct intermediate stages of neurogenesis. After their proliferative phase, GNPs exit the cell cycle to form a layer of cells that migrate tangentially, then undergo a morphological transformation that initiates radial migration through the molecular layer (ML) along glial fibers to their final laminar position (Rakic, 1971; Edmondson and Hatten, 1987; Komuro et al., 2001). In the outer EGL, the GNPs have a round morphology with multiple short processes (Manzini et al., 2006). As they migrate to the inner EGL, their cytoskeleton is reorganized to form two short horizontal processes that elongate during their journey to the ML (Figure 1E). After a brief latency at the ML, they acquire an elongated spindle shape and a vertical process (Komuro et al., 2001).

The maturation of CGNs and their migration requires polarization, which was carefully examined in two studies delineating role of Par complex in this process. The first study showed that manipulation of Pard $6 \alpha$ function, both in vitro and ex vivo, disrupts the actomyosin cytoskeleton and blocks radial migration of CGNs (Solecki et al., 2009). As expression of Pard3A polarity protein increases as the CGNs mature, the second study investigated its role in CGN migration (Famulski et al., 2010). Whereas loss of Pard3A impeded radial migration of CGNs, ectopic expression led to precocious migration. Further, Pard3A expression was shown to be regulated by E3 ubiquitin ligase seven in absentia homolog (Siah) 1 and 2 (Figure 2). Reciprocal expression of Siah and Pard3A in developing CGNs indicated that Siah negatively regulates Pard3A expression. This study also linked polarity proteins with adhesion of CGNs. In the epithelial cells, Pard3A binds to three members of the JAM family via its PDZ domain and recruits them to TJs to establish polarity (Ooshio et al., 2007). Utilizing live probe imaging, Famulski et al., demonstrated identical spatiotemporal expression of these proteins during CGN maturation and showed that JAM-C is necessary and sufficient for CGN exit from the EGL (Famulski et al., 2010). These results indicate that not only is cell adhesion crucial for guiding a neuron's migration path but the acquisition of adhesion by CGNs and loss of some of multipolar features reflects the MET-like process (Figure 1E). This is unique from other developing CNS structures where the newly born neurons lose polarity and require it upon reaching their final laminar position. A pertinent question that sequentially arises from these observations is how polarity is reorganized and how immature neurons initiate, implement and conclude this essential morphogenic event.

\section{SUMMARY}

Addressing the morphological changes observed in newly born neurons and its relevance in setting up the laminar structure of CNS raises some interesting questions. How the polar plasticity of newly born is regulated and what are the key factors that are involved in this process across the various developing CNS 
structures? Further in the developing cerebellum, how do the neurons born from the RGCs after adopting a multipolar migratory feature upon reaching the second GZ restore their polarity? Like the epithelial system is there a regulator whose expression temporally coincides with the CGNs reacquiring epithelial characteristics aka MET like processes. If so, what would be some of the targets of this MET like processes in developing neurons? Do these factors also play a role in differentiation and maturation of the neurons?

\section{ACKNOWLEDGMENTS}

We thank Sharon Naron for excellent editorial support in preparation of the manuscript and members of the Solecki lab for editing the manuscript. The Solecki Lab is funded by the American Lebanese Syrian Associated Charities (ALSAC), by grant \#1-FY12-455 from the March of Dimes, and by grant 1R01NS066936 from the National Institute of Neurological Disorders and Stroke (NINDS). The content is solely the responsibility of the authors and does not necessarily represent the official views of the NINDS or the National Institutes of Health.

\section{REFERENCES}

Aaku-Saraste, E., Hellwig, A., and Huttner, W. B. (1996). Loss of occludin and functional tight junctions, but not ZO-1, during neural tube closure-remodeling of the neuroepithelium prior to neurogenesis. Dev. Biol. 180, 664-679. doi: 10. 1006/dbio.1996.0336

Alaynick, W. A., Jessell, T. M., and Pfaff, S. L. (2011). SnapShot: spinal cord development. Cell 146, 178-178.e1. doi: 10.1016/j.cell.2011.06.038

Alves, C. H., Sanz, A. S., Park, B., Pellissier, L. P., Tanimoto, N., Beck, S. C., et al. (2013). Loss of CRB2 in the mouse retina mimics human retinitis pigmentosa due to mutations in the CRB1 gene. Hum. Mol. Genet. 22, 35-50. doi: 10. 1093/hmg/dds398

Angevine, J. B. Jr., and Sidman, R. L. (1961). Autoradiographic study of cell migration during histogenesis of cerebral cortex in the mouse. Nature 192, 766-768. doi: 10.1038/192766b0

Anton, E. S., Kreidberg, J. A., and Rakic, P. (1999). Distinct functions of alpha3 and alpha(v) integrin receptors in neuronal migration and laminar organization of the cerebral cortex. Neuron 22, 277-289. doi: 10.1016/s0896-6273(00)81089-2

Ayala, R., Shu, T., and Tsai, L. H. (2007). Trekking across the brain: the journey of neuronal migration. Cell 128, 29-43. doi: 10.1016/j.cell.2006.12.021

Baum, B., Settleman, J., and Quinlan, M. P. (2008). Transitions between epithelial and mesenchymal states in development and disease. Semin. Cell Dev. Biol. 19, 294-308. doi: 10.1016/j.semcdb.2008.02.001

Baye, L. M., and Link, B. A. (2007). Interkinetic nuclear migration and the selection of neurogenic cell divisions during vertebrate retinogenesis. J. Neurosci. 27, 10143-10152. doi: 10.1523/jneurosci.2754-07.2007

Baye, L. M., and Link, B. A. (2008). Nuclear migration during retinal development. Brain Res. 1192, 29-36. doi: 10.1016/j.brainres.2007.05.021

Bayer, S. A. (1986). Neurogenesis in the rat primary olfactory cortex. Int. J. Dev. Neurosci. 4, 251-271. doi: 10.1016/0736-5748(86)90063-8

Bayer, S. A. (1990). Neurogenetic patterns in the medial limbic cortex of the rat related to anatomical connections with the thalamus and striatum. Exp. Neurol. 107, 132-142. doi: 10.1016/0014-4886(90)90151-h

Bello, S. M., Millo, H., Rajebhosale, M., and Price, S. R. (2012). Catenin-dependent cadherin function drives divisional segregation of spinal motor neurons. J. Neurosci. 32, 490-505. doi: 10.1523/JNEUROSCI.4382-11.2012

Bi, W., Sapir, T., Shchelochkov, O. A., Zhang, F., Withers, M. A., Hunter, J. V., et al. (2009). Increased LIS1 expression affects human and mouse brain development. Nat. Genet. 41, 168-177. doi: 10.1038/ng.302

Bos, J. L., de Rooij, J., and Reedquist, K. A. (2001). Rap1 signalling: adhering to new models. Nat. Rev. Mol. Cell Biol. 2, 369-377. doi: 10.1038/35073073

Brault, V., Moore, R., Kutsch, S., Ishibashi, M., Rowitch, D. H., McMahon, A. P., et al. (2001). Inactivation of the beta-catenin gene by Wnt1-Cre-mediated deletion results in dramatic brain malformation and failure of craniofacial development. Development 128, 1253-1264.

Briscoe, J., and Novitch, B. G. (2008). Regulatory pathways linking progenitor patterning, cell fates and neurogenesis in the ventral neural tube. Philos. Trans. R. Soc. Lond. B Biol. Sci. 363, 57-70. doi: 10.1098/rstb.2006.2012

Bultje, R. S., Castaneda-Castellanos, D. R., Jan, L. Y., Jan, Y. N., Kriegstein, A. R., and Shi, S. H. (2009). Mammalian Par3 regulates progenitor cell asymmetric division via notch signaling in the developing neocortex. Neuron 63, 189-202. doi: 10.1016/j.neuron.2009.07.004

Bylund, M., Andersson, E., Novitch, B. G., and Muhr, J. (2003). Vertebrate neurogenesis is counteracted by Sox1-3 activity. Nat. Neurosci. 6, 1162-1168. doi: $10.1038 / \mathrm{nn} 1131$

Campbell, K., and Götz, M. (2002). Radial glia: multi-purpose cells for vertebrate brain development. Trends Neurosci. 25, 235-238. doi: 10.1016/s01662236(02)02156-2

Cappello, S., Attardo, A., Wu, X., Iwasato, T., Itohara, S., Wilsch-Bräuninger, M., et al. (2006). The Rho-GTPase cdc42 regulates neural progenitor fate at the apical surface. Nat. Neurosci. 9, 1099-1107. doi: 10.1038/nn1744

Chaffer, C. L., Thompson, E. W., and Williams, E. D. (2007). Mesenchymal to epithelial transition in development and disease. Cells Tissues Organs 185, 7-19. doi: 10.1159/000101298

Chenn, A., Zhang, Y. A., Chang, B. T., and McConnell, S. K. (1998). Intrinsic polarity of mammalian neuroepithelial cells. Mol. Cell. Neurosci. 11, 183-193. doi: $10.1006 / \mathrm{mcne} .1998 .0680$

Costa, M. R., Wen, G., Lepier, A., Schroeder, T., and Götz, M. (2008). Par-complex proteins promote proliferative progenitor divisions in the developing mouse cerebral cortex. Development 135, 11-22. doi: 10.1242/dev.009951

Das, R. M., and Storey, K. G. (2012). Mitotic spindle orientation can direct cell fate and bias Notch activity in chick neural tube. EMBO Rep. 13, 448-454. doi: 10. 1038/embor.2012.42

Das, R. M., and Storey, K. G. (2014). Apical abscission alters cell polarity and dismantles the primary cilium during neurogenesis. Science 343, 200-204. doi: $10.1126 /$ science. 1247521

Dasen, J. S., De Camilli, A., Wang, B., Tucker, P. W., and Jessell, T. M. (2008). Hox repertoires for motor neuron diversity and connectivity gated by a single accessory factor, FoxP1. Cell 134, 304-316. doi: 10.1016/j.cell.2008. 06.019

Dudok, J. J., Sanz, A. S., Lundvig, D. M., Sothilingam, V., Garrido, M. G., Klooster, J., et al. (2013). MPP3 regulates levels of PALS1 and adhesion between photoreceptors and Müller cells. Glia 61, 1629-1644. doi: 10.1002/glia.22545

Edmondson, J. C., and Hatten, M. E. (1987). Glial-guided granule neuron migration in vitro: a high-resolution time-lapse video microscopic study. $J$. Neurosci. 7, 1928-1934.

Famulski, J. K., Trivedi, N., Howell, D., Yang, Y., Tong, Y., Gilbertson, R., et al. (2010). Siah regulation of Pard $3 \mathrm{~A}$ controls neuronal cell adhesion during germinal zone exit. Science 330, 1834-1838. doi: 10.1126/science.1198480

Farkas, L. M., and Huttner, W. B. (2008). The cell biology of neural stem and progenitor cells and its significance for their proliferation versus differentiation during mammalian brain development. Curr. Opin. Cell Biol. 20, 707-715. doi: 10.1016/j.ceb.2008.09.008

Ferland, R. J., Cherry, T. J., Preware, P. O., Morrisey, E. E., and Walsh, C. A. (2003). Characterization of Foxp2 and Foxp 1 mRNA and protein in the developing and mature brain. J. Comp. Neurol. 460, 266-279. doi: 10.1002/cne.10654

Frade, J. M. (2002). Interkinetic nuclear movement in the vertebrate neuroepithelium: encounters with an old acquaintance. Prog. Brain Res. 136, 67-71. doi: 10.1016/s0079-6123(02)36007-2

Franco, S. J., Martinez-Garay, I., Gil-Sanz, C., Harkins-Perry, S. R., and Müller, U. (2011). Reelin regulates cadherin function via Dab1/Rapl to control neuronal migration and lamination in the neocortex. Neuron 69, 482-497. doi: 10.1016/j. neuron.2011.01.003

Fu, X., Sun, H., Klein, W. H., and Mu, X. (2006). Beta-catenin is essential for lamination but not neurogenesis in mouse retinal development. Dev. Biol. 299, 424-437. doi: 10.1016/j.ydbio.2006.08.015

Gao, W. Q., and Hatten, M. E. (1994). Immortalizing oncogenes subvert the establishment of granule cell identity in developing cerebellum. Development 120, 1059-1070.

Ge, W., He, F., Kim, K. J., Blanchi, B., Coskun, V., Nguyen, L., et al. (2006). Coupling of cell migration with neurogenesis by proneural bHLH factors. Proc. Natl. Acad. Sci. US A 103, 1319-1324. doi: 10.1073/pnas.0510419103 
Götz, M. (2003). Glial cells generate neurons-master control within CNS regions: developmental perspectives on neural stem cells. Neuroscientist 9, 379-397. doi: $10.1177 / 1073858403257138$

Götz, M., and Huttner, W. B. (2005). The cell biology of neurogenesis. Nat. Rev. Mol. Cell Biol. 6, 777-788. doi: 10.1038/nrm1739

Graham, V., Khudyakov, J., Ellis, P., and Pevny, L. (2003). SOX2 functions to maintain neural progenitor identity. Neuron 39, 749-765. doi: 10.1016/s08966273(03)00497-5

Graus-Porta, D., Blaess, S., Senften, M., Littlewood-Evans, A., Damsky, C., Huang, Z., et al. (2001). Betal-class integrins regulate the development of laminae and folia in the cerebral and cerebellar cortex. Neuron 31, 367-379. doi: 10 . 1016/s0896-6273(01)00374-9

Hallonet, M. E., and Le Douarin, N. M. (1993). Tracing neuroepithelial cells of the mesencephalic and metencephalic alar plates during cerebellar ontogeny in quail-chick chimaeras. Eur. J. Neurosci. 5, 1145-1155. doi: 10.1111/j.1460-9568. 1993.tb00969.x

Hatakeyama, J., Wakamatsu, Y., Nagafuchi, A., Kageyama, R., Shigemoto, R., and Shimamura, K. (2014). Cadherin-based adhesions in the apical endfoot are required for active Notch signaling to control neurogenesis in vertebrates. Development 141, 1671-1682. doi: 10.1242/dev.102988

Hatten, M. E. (1999). Central nervous system neuronal migration. Annu. Rev. Neurosci. 22, 511-539. doi: 10.1146/annurev.neuro.22.1.511

Haubensak, W., Attardo, A., Denk, W., and Huttner, W. B. (2004). Neurons arise in the basal neuroepithelium of the early mammalian telencephalon: a major site of neurogenesis. Proc. Natl. Acad. Sci. U S A 101, 3196-3201. doi: 10.1073/pnas. 0308600100

Heasman, S. J., and Ridley, A. J. (2008). Mammalian Rho GTPases: new insights into their functions from in vivo studies. Nat. Rev. Mol. Cell Biol. 9, 690-701. doi: $10.1038 / \mathrm{nrm} 2476$

Heng, J. I., Nguyen, L., Castro, D. S., Zimmer, C., Wildner, H., Armant, O., et al. (2008). Neurogenin 2 controls cortical neuron migration through regulation of Rnd2. Nature 455, 114-118. doi: 10.1038/nature07198

Herder, C., Swiercz, J. M., Müller, C., Peravali, R., Quiring, R., Offermanns, S., et al. (2013). ArhGEF18 regulates RhoA-Rock2 signaling to maintain neuroepithelial apico-basal polarity and proliferation. Development 140, 2787-2797. doi: 10.1242/dev.096487

Heynen, S. R., Meneau, I., Caprara, C., Samardzija, M., Imsand, C., Levine, E. M., et al. (2013). CDC42 is required for tissue lamination and cell survival in the mouse retina. PLoS One 8:e53806. doi: 10.1371/journal.pone.0053806

Huttner, W. B., and Brand, M. (1997). Asymmetric division and polarity of neuroepithelial cells. Curr. Opin. Neurobiol. 7, 29-39. doi: 10.1016/s09594388(97)80117-1

Imai, F., Hirai, S., Akimoto, K., Koyama, H., Miyata, T., Ogawa, M., et al. (2006). Inactivation of aPKClambda results in the loss of adherens junctions in neuroepithelial cells without affecting neurogenesis in mouse neocortex. Development 133, 1735-1744. doi: 10.1242/dev.02330

Ishiuchi, T., Misaki, K., Yonemura, S., Takeichi, M., and Tanoue, T. (2009). Mammalian fat and Dachsous cadherins regulate apical membrane organization in the embryonic cerebral cortex. J. Cell Biol. 185, 959-967. doi: 10.1083/jcb. 200811030

Itoh, Y., Moriyama, Y., Hasegawa, T., Endo, T. A., Toyoda, T., and Gotoh, Y. (2013). Scratch regulates neuronal migration onset via an epithelial-mesenchymal transition-like mechanism. Nat. Neurosci. 16, 416-425. doi: 10.1038/ nn. 3336

Ivanovitch, K., Cavodeassi, F., and Wilson, S. W. (2013). Precocious acquisition of neuroepithelial character in the eye field underlies the onset of eye morphogenesis. Dev. Cell 27, 293-305. doi: 10.1016/j.devcel.2013.09.023

Jossin, Y. (2011). Polarization of migrating cortical neurons by Rapl and Ncadherin: revisiting the model for the Reelin signaling pathway. Small GTPases 2, 322-328. doi: 10.4161/sgtp.18283

Jossin, Y., and Cooper, J. A. (2011). Reelin, Rap1 and N-cadherin orient the migration of multipolar neurons in the developing neocortex. Nat. Neurosci. 14, 697-703. doi: 10.1038/nn.2816

Junghans, D., Hack, I., Frotscher, M., Taylor, V., and Kemler, R. (2005). Betacatenin-mediated cell-adhesion is vital for embryonic forebrain development. Dev. Dyn. 233, 528-539. doi: 10.1002/dvdy.20365

Kadowaki, M., Nakamura, S., Machon, O., Krauss, S., Radice, G. L., and Takeichi, M. (2007). N-cadherin mediates cortical organization in the mouse brain. Dev. Biol. 304, 22-33. doi: 10.1016/j.ydbio.2006.12.014
Koike, C., Nishida, A., Akimoto, K., Nakaya, M. A., Noda, T., Ohno, S., et al. (2005). Function of atypical protein kinase $\mathrm{C}$ lambda in differentiating photoreceptors is required for proper lamination of mouse retina. J. Neurosci. 25, 10290-10298. doi: 10.1523/jneurosci.3657-05.2005

Komuro, H., Yacubova, E., Yacubova, E., and Rakic, P. (2001). Mode and tempo of tangential cell migration in the cerebellar external granular layer. J. Neurosci. 21, 527-540.

Lamouille, S., Xu, J., and Derynck, R. (2014). Molecular mechanisms of epithelialmesenchymal transition. Nat. Rev. Mol. Cell Biol. 15, 178-196. doi: 10. $1038 /$ nrm 3758

Loosli, F. (2013). ArhGEF18 regulated Rho signaling in vertebrate retina development. Small GTPases 4, 242-246. doi: 10.4161/sgtp.27061

Malatesta, P., Hartfuss, E., and Gotz, M. (2000). Isolation of radial glial cells by fluorescent-activated cell sorting reveals a neuronal lineage. Development 127, 5253-5263.

Manabe, N., Hirai, S., Imai, F., Nakanishi, H., Takai, Y., and Ohno, S. (2002). Association of ASIP/mPAR-3 with adherens junctions of mouse neuroepithelial cells. Dev. Dyn. 225, 61-69. doi: 10.1002/dvdy.10139

Mani, S. A., Yang, J., Brooks, M., Schwaninger, G., Zhou, A., Miura, N., et al. (2007). Mesenchyme Forkhead 1 (FOXC2) plays a key role in metastasis and is associated with aggressive basal-like breast cancers. Proc. Natl. Acad. Sci. U S A 104, 10069-10074. doi: 10.1073/pnas.0703900104

Manzini, M. C., Ward, M. S., Zhang, Q., Lieberman, M. D., and Mason, C. A. (2006). The stop signal revised: immature cerebellar granule neurons in the external germinal layer arrest pontine mossy fiber growth. J. Neurosci. 26, 6040-6051. doi: 10.1523/jneurosci.4815-05.2006

Marín, O., and Rubenstein, J. L. (2001). A long, remarkable journey: tangential migration in the telencephalon. Nat. Rev. Neurosci. 2, 780-790. doi: 10. 1038/35097509

Métin, C., Vallee, R. B., Rakic, P., and Bhide, P. G. (2008). Modes and mishaps of neuronal migration in the mammalian brain. J. Neurosci. 28, 11746-11752. doi: 10.1523/jneurosci.3860-08.2008

Mione, M. C., Cavanagh, J. F., Harris, B., and Parnavelas, J. G. (1997). Cell fate specification and symmetrical/asymmetrical divisions in the developing cerebral cortex. J. Neurosci. 17, 2018-2029.

Miyata, T. (2008). Development of three-dimensional architecture of the neuroepithelium: role of pseudostratification and cellular 'community'. Dev. Growth Differ. 50, (Suppl. 1), S105-S112. doi: 10.1111/j.1440-169x.2007. 00980.x

Mizoguchi, A., Nakanishi, H., Kimura, K., Matsubara, K., Ozaki-Kuroda, K., Katata, T., et al. (2002). Nectin: an adhesion molecule involved in formation of synapses. J. Cell Biol. 156, 555-565. doi: 10.1083/jcb.200103113

Mukouyama, Y. S., Deneen, B., Lukaszewicz, A., Novitch, B. G., Wichterle, H., Jessell, T. M., et al. (2006). Olig2+ neuroepithelial motoneuron progenitors are not multipotent stem cells in vivo. Proc. Natl. Acad. Sci. U S A 103, 1551-1556. doi: 10.1073/pnas.0510658103

Nadarajah, B., Alifragis, P., Wong, R. O., and Parnavelas, J. G. (2003). Neuronal migration in the developing cerebral cortex: observations based on real-time imaging. Cereb. Cortex 13, 607-611. doi: 10.1093/cercor/13.6.607

Nadarajah, B., and Parnavelas, J. G. (2002). Modes of neuronal migration in the developing cerebral cortex. Nat. Rev. Neurosci. 3, 423-432. doi: 10.1038/ nrn 845

Nelson, W. J. (2009). Remodeling epithelial cell organization: transitions between front-rear and apical-basal polarity. Cold Spring Harb. Perspect. Biol. 1:a000513. doi: 10.1101/cshperspect.a000513

Nishimura, T., Kato, K., Yamaguchi, T., Fukata, Y., Ohno, S., and Kaibuchi, K. (2004). Role of the PAR-3-KIF3 complex in the establishment of neuronal polarity. Nat. Cell Biol. 6, 328-334. doi: 10.1038/ncb1118

Ohata, S., Aoki, R., Kinoshita, S., Yamaguchi, M., Tsuruoka-Kinoshita, S., Tanaka, H., et al. (2011). Dual roles of Notch in regulation of apically restricted mitosis and apicobasal polarity of neuroepithelial cells. Neuron 69, 215-230. doi: 10 . 1016/j.neuron.2010.12.026

Ooshio, T., Fujita, N., Yamada, A., Sato, T., Kitagawa, Y., Okamoto, R., et al. (2007). Cooperative roles of Par-3 and afadin in the formation of adherens and tight junctions. J. Cell Sci. 120, 2352-2365. doi: 10.1242/jcs.03470

Ozdamar, B., Bose, R., Barrios-Rodiles, M., Wang, H. R., Zhang, Y., and Wrana, J. L. (2005). Regulation of the polarity protein Par6 by TGFbeta receptors controls epithelial cell plasticity. Science 307, 1603-1609. doi: 10.1126/science. 1105718 
Pacary, E., Azzarelli, R., and Guillemot, F. (2013). Rnd3 coordinates early steps of cortical neurogenesis through actin-dependent and -independent mechanisms. Nat. Commun. 4:1635. doi: 10.1038/ncomms2614

Pacary, E., Heng, J., Azzarelli, R., Riou, P., Castro, D., Lebel-Potter, M., et al. (2011). Proneural transcription factors regulate different steps of cortical neuron migration through Rnd-mediated inhibition of RhoA signaling. Neuron 69, 1069-1084. doi: 10.1016/j.neuron.2011.02.018

Palmesino, E., Rousso, D. L., Kao, T. J., Klar, A., Laufer, E., Uemura, O., et al. (2010). Foxpl and lhx1 coordinate motor neuron migration with axon trajectory choice by gating Reelin signalling. PLoS Biol. 8:e1000446. doi: 10.1371/journal.pbio. 1000446

Park, B., Alves, C. H., Lundvig, D. M., Tanimoto, N., Beck, S. C., Huber, G., et al. (2011). PALS1 is essential for retinal pigment epithelium structure and neural retina stratification. J. Neurosci. 31, 17230-17241. doi: 10.1523/jneurosci.443011.2011

Pellikka, M., Tanentzapf, G., Pinto, M., Smith, C., McGlade, C. J., Ready, D. F., et al. (2002). Crumbs, the Drosophila homologue of human CRB1/RP12, is essential for photoreceptor morphogenesis. Nature 416, 143-149. doi: 10.1038/nature721

Perez-Moreno, M., and Fuchs, E. (2006). Catenins: keeping cells from getting their signals crossed. Dev. Cell 11, 601-612. doi: 10.1016/j.devcel.2006.10.010

Rakic, P. (1971). Neuron-glia relationship during granule cell migration in developing cerebellar cortex. A Golgi and electronmicroscopic study in Macacus Rhesus. J. Comp. Neurol. 141, 283-312. doi: 10.1002/cne.901410303

Rakic, P. (2009). Evolution of the neocortex: a perspective from developmental biology. Nat. Rev. Neurosci. 10, 724-735. doi: 10.1038/nrn2719

Roussel, M. F., and Hatten, M. E. (2011). Cerebellum development and medulloblastoma. Curr. Top. Dev. Biol. 94, 235-282. doi: 10.1016/B978-0-12380916-2.00008-5

Rousso, D. L., Gaber, Z. B., Wellik, D., Morrisey, E. E., and Novitch, B. G. (2008). Coordinated actions of the forkhead protein Foxp1 and Hox proteins in the columnar organization of spinal motor neurons. Neuron 59, 226-240. doi: 10. 1016/j.neuron.2008.06.025

Rousso, D. L., Pearson, C. A., Gaber, Z. B., Miquelajauregui, A., Li, S., PorteraCailliau, C., et al. (2012). Foxp-mediated suppression of N-cadherin regulates neuroepithelial character and progenitor maintenance in the CNS. Neuron 74, 314-330. doi: 10.1016/j.neuron.2012.02.024

Samarin, S., and Nusrat, A. (2009). Regulation of epithelial apical junctional complex by Rho family GTPases. Front. Biosci. (Landmark Ed.) 14, 1129-1142. doi: $10.2741 / 3298$

Severson, E. A., Lee, W. Y., Capaldo, C. T., Nusrat, A., and Parkos, C. A. (2009). Junctional adhesion molecule A interacts with Afadin and PDZ-GEF2 to activate Rap1A, regulate betal integrin levels and enhance cell migration. Mol. Biol. Cell 20, 1916-1925. doi: 10.1091/mbc.e08-10-1014

Shoukimas, G. M., and Hinds, J. W. (1978). The development of the cerebral cortex in the embryonic mouse: an electron microscopic serial section analysis. J. Comp. Neurol. 179, 795-830. doi: 10.1002/cne.901790407

Solecki, D. J., Trivedi, N., Govek, E. E., Kerekes, R. A., Gleason, S. S., and Hatten, M. E. (2009). Myosin II motors and F-actin dynamics drive the coordinated movement of the centrosome and soma during CNS glial-guided neuronal migration. Neuron 63, 63-80. doi: 10.1016/j.neuron.2009.05.028

Thiery, J. P., and Sleeman, J. P. (2006). Complex networks orchestrate epithelialmesenchymal transitions. Nat. Rev. Mol. Cell Biol. 7, 131-142. doi: 10. 1038/nrm1835

Tsukita, S., and Furuse, M. (1999). Occludin and claudins in tight-junction strands: leading or supporting players? Trends Cell Biol. 9, 268-273. doi: 10.1016/s09628924(99)01578-0
Tsukita, S., Furuse, M., and Itoh, M. (1999). Structural and signalling molecules come together at tight junctions. Curr. Opin. Cell Biol. 11, 628-633. doi: 10. 1016/s0955-0674(99)00016-2

Umeda, K., Matsui, T., Nakayama, M., Furuse, K., Sasaki, H., Furuse, M., et al. (2004). Establishment and characterization of cultured epithelial cells lacking expression of ZO-1. J. Biol. Chem. 279, 44785-44794. doi: 10.1074/jbc. $\mathrm{m} 406563200$

van de Pavert, S. A., Sanz, A. S., Aartsen, W. M., Vos, R. M., Versteeg, I., Beck, S. C., et al. (2007). Crb1 is a determinant of retinal apical Muller glia cell features. Glia 55, 1486-1497. doi: 10.1002/glia.20561

Wang, X., Nie, J., Zhou, Q., Liu, W., Zhu, F., Chen, W., et al. (2008). Downregulation of Par-3 expression and disruption of Par complex integrity by TGF-beta during the process of epithelial to mesenchymal transition in rat proximal epithelial cells. Biochim. Biophys. Acta 1782, 51-59. doi: 10.1016/j.bbadis.2007.11.002

Wilson, S. W., and Rubenstein, J. L. (2000). Induction and dorsoventral patterning of the telencephalon. Neuron 28, 641-651. doi: 10.1016/s0896-6273(00)00171-9

Wingate, R. J. (2001). The rhombic lip and early cerebellar development. Curr. Opin. Neurobiol. 11, 82-88. doi: 10.1016/s0959-4388(00)00177-x

Yokota, Y., Eom, T. Y., Stanco, A., Kim, W. Y., Rao, S., Snider, W. D., et al. (2010). Cdc42 and Gsk3 modulate the dynamics of radial glial growth, inter-radial glial interactions and polarity in the developing cerebral cortex. Development 137, 4101-4110. doi: 10.1242/dev.048637

Zander, M. A., Burns, S. E., Yang, G., Kaplan, D. R., and Miller, F. D. (2014a). Snail coordinately regulates downstream pathways to control multiple aspects of mammalian neural precursor development. J. Neurosci. 34, 5164-5175. doi: 10. 1523/jneurosci.0370-14.2014

Zander, M. A., Cancino, G. I., Gridley, T., Kaplan, D. R., and Miller, F. D. (2014b). The Snail transcription factor regulates the numbers of neural precursor cells and newborn neurons throughout mammalian life. PLoS One 9:e104767. doi: 10.1371/journal.pone.0104767

Zappone, M. V., Galli, R., Catena, R., Meani, N., De Biasi, S., Mattei, E., et al. (2000). Sox2 regulatory sequences direct expression of a (beta)-geo transgene to telencephalic neural stem cells and precursors of the mouse embryo, revealing regionalization of gene expression in CNS stem cells. Development 127, 23672382.

Zhadanov, A. B., Provance, D. W. Jr., Speer, C. A., Coffin, J. D., Goss, D., Blixt, J. A., et al. (1999). Absence of the tight junctional protein AF-6 disrupts epithelial cell-cell junctions and cell polarity during mouse development. Curr. Biol. 9, 880-888. doi: 10.1016/s0960-9822(99)80392-3

Conflict of Interest Statement: The authors declare that the research was conducted in the absence of any commercial or financial relationships that could be construed as a potential conflict of interest.

Received: 17 December 2014; accepted: 10 February 2015; published online: 04 March 2015.

Citation: Singh S and Solecki DJ (2015) Polarity transitions during neurogenesis and germinal zone exit in the developing central nervous system. Front. Cell. Neurosci. 9:62. doi: 10.3389/fncel.2015.00062

This article was submitted to the journal Frontiers in Cellular Neuroscience.

Copyright $\odot 2015$ Singh and Solecki. This is an open-access article distributed under the terms of the Creative Commons Attribution License (CC BY). The use, distribution and reproduction in other forums is permitted, provided the original author(s) or licensor are credited and that the original publication in this journal is cited, in accordance with accepted academic practice. No use, distribution or reproduction is permitted which does not comply with these terms. 